\title{
Legitimacy and Implications of Reducing Colletotrichum kahawae to Subspecies in Plant Pathology
}

\author{
Dora Batista ${ }^{1,2,3 *}$, Diogo N. Silva ${ }^{1,3}$, Ana Vieira ${ }^{1,3}$, Ana Cabral ${ }^{1,2}$, Ana S. Pires ${ }^{1}$, \\ Andreia Loureiro ${ }^{1,2}$, Leonor Guerra-Guimarães ${ }^{1,2}$, Ana P. Pereira ${ }^{1}$, Helena Azinheira ${ }^{1,2}$, \\ Pedro Talhinhas ${ }^{1,2}$, Maria do Céu Silva ${ }^{1,2}$ and Vitor Várzea ${ }^{1,2}$ \\ ${ }^{1}$ Centro de Investigação das Ferrugens do Cafeeiro, Instituto Superior de Agronomia, Universidade de Lisboa, Oeiras, \\ Portugal, ${ }^{2}$ Linking Landscape, Environment, Agriculture and Food, Instituto Superior de Agronomia, Universidade de Lisboa, \\ Lisboa, Portugal, ${ }^{3}$ Computational Biology and Population Genomics Group, Centre for Ecology, Evolution and Environmental \\ Changes, Faculdade de Ciências, Universidade de Lisboa, Lisboa, Portugal
}

Keywords: coffee berry disease, anthracnose, Colletotrichum taxonomy, Colletotrichum gloeosporioides species complex, Colletotrichum kahawae subsp. kahawae, Colletotrichum kahawae subsp. ciggaro

Colletotrichum kahawae Waller and Bridge is a highly aggressive and specialized fungal pathogen of coffee, causing the devastating Coffee Berry Disease (CBD), particularly at high altitudes. The disease arises from the unique ability of the pathogen to infect green developing coffee berries. This pathogen is currently confined to the African continent in all countries that grow Arabica coffee (Coffea arabica L.), leading to up to $80 \%$ yield losses, if no control measures are applied (Silva et al., 2006; Vossen and Walyaro, 2009; Hindorf and Omondi, 2011). For such huge economic impact, it is ranked as a quarantine pathogen and even as a biological weapon (Australia Group, 2014). Consequently, the pathogen's potential dispersal to other Arabica coffee cultivation regions is greatly feared, particularly to those at high altitude also found in Latin America and Asia. Recently, this recognized species was brought down to a subspecific level (C. kahawae subsp. kahawae) based on molecular data (Weir et al., 2012), clustering together with a generalist and cosmopolitan group of Colletotrichum isolates unable to cause CBD (C. kahawae subsp. ciggaro). Since then a growing number of studies have reported the identification of $C$. kahawae in various hosts and regions of the world (Liu et al., 2013; Afanador-Kafuri et al., 2014; Mosca et al., 2014; Schena et al., 2014; Ismail et al., 2015; Garibaldi et al., 2016a,b; Perrone et al., 2016). Although these reports are referring to C. kahawae subsp. ciggaro, some of them could not distinguish the pathogen at the subspecific level, and this is leading to a wave of confusion of whether the long accepted species C. kahawae, the CBD pathogen, has escaped from Africa and extended its host range. Given the extreme impact that this situation may trigger and the subsequent biosecurity implications, there is a practical need to completely distinguish these pathogens taxonomically as to avoid the risk of misidentification, and caution should be taken on assigning/reassigning taxonomic ranking and nomenclature. Here we consider the evidences sustaining and contradicting the classification proposed by Weir et al. (2012), and discuss the risks and practical implications of changing the CBD pathogen's species status in a plant pathology context.

After a long period of confusion in nomenclature, Colletotrichum kahawae (epithet derived from the Swahili word for coffee) was proposed by Waller et al. (1993) as a formal name to refer specifically to Colletotrichum isolates causing CBD and taxonomically distinguishing them from other Colletotrichum strains found on coffee. The CBD pathogen was previously known as either C. coffeanum var. virulans (Rayner, 1952), a form of C. coffeanum (Nutman and Roberts, 1960), CBD-strain (Gibbs, 1969), or C. coffeanum Noack sensu Hindorf (Hindorf, 1970, 1974). Interestingly, the name C. coffeanum was not based on type material associated with CBD, but on samples from Brazil where the disease does not exist, and it clearly referred to C. gloeosporioides 
(Waller et al., 1993), thus in view of its distinctive characteristics the applicability of these names was questionable. Waller et al. (1993) argued that, although closely related with C. gloeosporioides, the CBD pathogen is sufficiently distinct in pathogenicity and related ecology, morphological, cultural, and biochemical characteristics to warrant recognition as a distinct species. This was further confirmed based on multi-locus phylogenies (Prihastuti et al., 2009; Silva et al., 2012a).

Recently, an alteration of the species taxonomic status of C. kahawae was proposed by Weir et al. (2012), placing the CBD pathogen again in an elusive position. Using a multi-locus sequencing approach, both Silva et al. (2012b) and Weir et al. (2012) showed that the CBD pathogen share a remarkable genetic similarity with a group of isolates found on a wide range of hosts and geographical origins [referred as Undescribed Group 1 (UG1) by Silva et al., 2012b]. Indeed, for a set of barcoding gene sequences (ACT, CAL, CHS-1, GAPDH, TUB2, SOD2, and ITS) the two taxa are indistinguishable. In their revision of the C. gloeosporioides species complex, Weir et al. (2012) accepted species according to the genealogical concordance phylogenetic species recognition (Taylor et al., 2000) criteria alone, and as such both groups should indeed be regarded as a single species. Thus, standing solely from a phylogenetic point of view, Weir et al. (2012) recognized them as two subspecies: the CBD pathogen (C. kahawae subsp. kahawae) and the genetic similar Colletotrichum isolates (C. kahawae subsp. ciggaro; as a side note to the nomenclature chosen by the authors, the Portuguese word for cigarette is cigarro). However, as further demonstrated by Silva et al. (2012b) through population genetic, evolutionary, and pathological data, these clearly represent ecologically distinct and reproductively isolated biological entities, which have separated quite recently. According to the authors, UG1 (C. kahawae subsp. ciggaro sensu Weir et al., 2012) seems to be a sibling lineage from which $C$. kahawae may have undergone a very recent ecological speciation through host jump into C. arabica, and thus still share a considerable genetic background, although have become quite differentiated, as shown by the significant and elevated differentiation indexes across all studied loci and a complete segregation of polymorphic sites (Silva et al., 2012b). Its unparalleled adaptation of infecting green coffee berries enables the $\mathrm{CBD}$ pathogen to occupy a unique ecological niche, which separates it on a functional level from all other Colletotrichum species (Figure 1). Quite a list of distinctive features can follow. In addition to its biology and slow growth form, the CBD pathogen can be distinguished metabolically by its inability to use either citrate or tartrate as a sole carbon source (Waller et al., 1993 and references herein; Varzea et al., 2002; Weir et al., 2012). At the genetic level, single genes or a combination of genes, specifically glutamine synthetase (GS) (Weir et al., 2012), mating type 1-2-1 (MAT1-2-1), and a fragment of DNA lyase Apn2 (Apn25L) (Silva et al., 2012b), reliably distinguish the CBD pathogen, as well as the genome size (Pires et al., 2016).

In the light of all these evidences reinforcing the differentiation of the $\mathrm{CBD}$ pathogen as a distinct and quite separate taxon in the coffee mycobiota, the taxonomic treatment proposed by Weir et al. (2012) is debatable and should be carefully interpreted. The authors acknowledge its

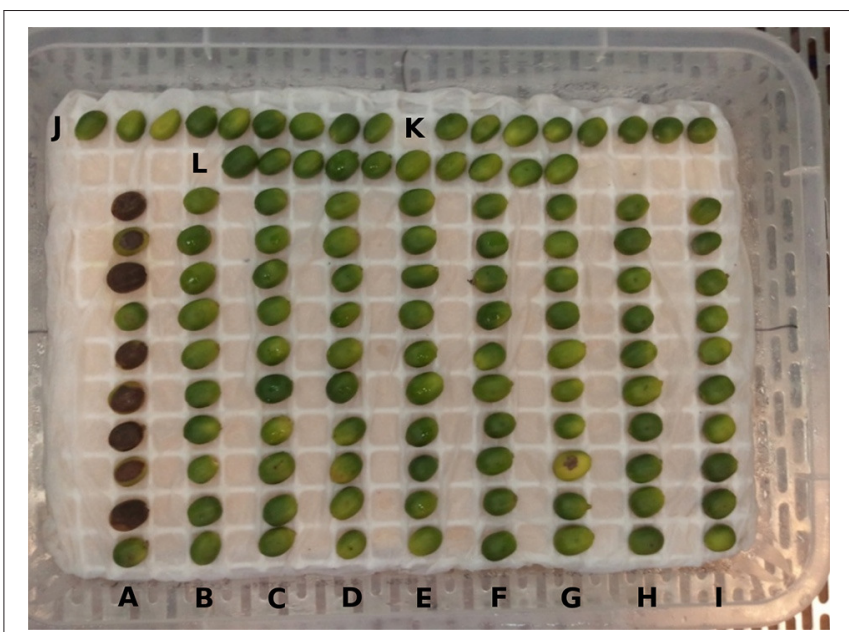

FIGURE 1 | Pathogenicity tests on coffee green berries showing that only C. kahawae subsp. kahawae isolates produced necrotic and sunken lesions characteristic of coffee berry disease symptoms (isolate Cam1, A), when compared to isolates from C. kahawae subsp. ciggaro [ICMP 17922 (C); ICMP 18534 (E); ICMP 12953 (F); ICMP 18539 (G)] and from other close phylogenetic groups [Cg432 (B); Glomerella cingulata "f. sp. camelliae" ICMP 18542 (D); C. aotearoa, ICMP 18530 (H), ICMP 18537 (I), ICMP 18541 (J), ICMP 18536 (K), ICMP 17326 (L)]. Isolates (C-L) were kindly provided by Bevan Weir and Peter Johnston (Landcare Research, Auckland, New Zealand), and Cg432 by Ana Paula Ramos (Instituto Superior de Agronomia, Universidade de Lisboa, Lisboa, Portugal).

distinctive features and biosecurity importance and to reflect this particularity retain a distinct taxonomic label for the CBD pathogen, while choosing to accept it only as biologically specialized population within a monophyletic supported species. It is well known that the species concepts are still in a state of flux in Colletotrichum taxonomy (Crouch et al., 2014), and particularly the low levels of genetic divergence across the C. gloeosporioides complex provide a technical challenge for species resolution (Silva et al., 2012a). Even more so, Weir et al. (2012) recognize the continuing uncertainty about sensible species limits within the C. gloeosporioides complex and that more powerful genes than the limited set sampled in their study, may provide finer resolution within the species-level clades that they accept. Precisely for this reason, extreme caution should be taken when assigning taxonomic ranking within members of the C. gloesporioides complex and additional data should be consider to complement genetic diversity and phylogenetic information, especially when biosecurity issues are at stake. In this case, the name Colletotrichum kahawae has a strong practical meaning and an indissoluble connection with the coffee disease. Bringing a volatile group of fungi able to infect a wide range of organs and hosts worldwide under the same specific epithet (which means coffee), is likely to disrupt the accuracy required in the nomenclature for pathogen identification and cause a great deal of confusion, even if distinction at the subspecific level is provided.

As a predictable consequence, several disease notes have reported the identification of C. kahawae in various hosts and regions out of Africa, including Rubus glaucus in Colombia 
(Afanador-Kafuri et al., 2014), olive, mango, and mandarin in Italy (Mosca et al., 2014; Schena et al., 2014; Ismail et al., 2015; Perrone et al., 2016), Banksia sp. in Portugal (Madeira) and Spain, and Leucospermum sp. in the USA (Hawaii) (Liu et al., 2013). While these studies assigned their isolates to C. kahawae subsp. ciggaro, others did not applied the genetic markers able to distinguish the two subspecies, and dangerously reported the presence of $C$. kahawae (no subspecies given) on rocket (Eruca sativa) (Garibaldi et al., 2016a) and American sweetgum (Liquidambar stryraciflua) (Garibaldi et al., 2016b) in Italy, suggesting the adoption of measures to contain the spread of the pathogen. The current classification promotes the chance of misidentification and uncertainty of the taxon addressed, leading to inaccurate records, distress within the coffee research and technical community, and severe biosecurity implications. On one hand, this might provoke a situation of assuming that C. kahawae has become able of infecting other hosts, and as such, of causing a devastating disease similar to that in coffee. On the other, C. kahawae is listed under strict quarantine regulations in many coffee growing countries, such as Australia and China (Jayawardena et al., 2016), and upon the information of the pathogen's potential detection, a state of emergency could be declared, particularly in major producing countries which have their economy strongly based on coffee production. Accurate naming of Colletotrichum to species level is crucial with regard to species identification and diversity, plant pathology and quarantine, agriculture, biocontrol, plant breeding, whole genome sequencing, developing, and maintaining knowledge data bases, commercial applications and understanding evolutionary history (Jayawardena et al.,

\section{REFERENCES}

Afanador-Kafuri, L., González, A., Ga-án, L., Mejía, J. F., Cardona, N., and Alvarez, E. (2014). Characterization of the Colletotrichum species causing anthracnose in andean blackberry in Colombia. Plant Dis. 98, 1503-1513. doi: 10.1094/PDIS-07-13-0752-RE

Australia Group (2014). Australia Group Common Control List Handbook Volume II: Biological Weapons-Related Common Control Lists. Available online at: http://www.australiagroup.net

Crouch, J., O'Connell, R., Gan, P., Buiate, E., Torres, M. F., Beirn, L., et al. (2014). "The genomics of Colletotrichum," in Genomics of Plant-Associated Fungi: Monocot Pathogens, eds R. A. Dean, A. Lichens-Park, and C. Kole (Berlin: Springer-Verlag), 69-102.

Garibaldi, A., Gilardi, G., Franco-Ortega, S., and Gullino, M. L. (2016b). First report of leaf spot caused by Colletotrichum kahawae on american sweetgum (Liquidambar styraciflua) in Italy. J. Plant Pathol. 98:36. doi: 10.4454/JPP.V98I2.036

Garibaldi, A., Gilardi, G., Puglisi, I., Cacciola, S. O., and Gullino, M. L. (2016a). First report of leaf spot caused by Colletotrichum kahawae on cultivated rocket (Eruca sativa) in Italy. Plant Dis. 100:1240. doi: 10.1094/PDIS-11-151243-PDN

Gibbs, J. N. (1969). Inoculum sources for coffee berry disease. Ann. Appl. Biol. 64, 515-522. doi: 10.1111/j.1744-7348.1969.tb02900.x

Hindorf, H. (1970). Colletotrichum spp. isolated from Coffea arabica L. in Kenya. Z. Pflanzenkrankh. Pflanzenschutz 77, 328-331.

Hindorf, H. (1974). Colletotrichum-Arten aus dem Kaffeeanbaugebiet von Kiambu in Kenia/ Colletotrichum spp. collected in coffee growing areas of the Klambu-district of Kenya. Z. Pflanzenkrankh. Pflanzenschutz 81, $108-113$.
2016). If cryptic species are mistaken for a single species, then the species' integrity and understanding is compromised. Whether the C. kahawae subspecies' recognized by Weir et al. (2012) are after all genetically good species, will most likely be only suitably resolved with genomic data, an endeavor that is close to be accomplished (Vieira et al., 2016). For now, it should be considered that, as shown by Silva et al. (2012b) and Pires et al. (2016), notwithstanding the remarkable genetic similarity, there are enough evidences to accept them as distinct species, and in this light they would be better described and viewed as cryptic species.

\section{AUTHOR CONTRIBUTIONS}

$\mathrm{DB}, \mathrm{MCS}$, and VV conceived the idea. DB, DNS, AV, AC, ASP, AL, LGG, APP, HA, PT, MCS, and VV contributed to develop the concept and structure of the manuscript. DB wrote the manuscript. DNS prepared and edited the figure. DNS, AV, AL, LGG, HA, PT, MCS, and VV provided revisions to the manuscript. All authors read and approved the work for publication. The views and opinion presented in this article are those of the authors.

\section{ACKNOWLEDGMENTS}

Fundação para a Ciência e a Tecnologia (FCT, Portugal) is acknowledged for grants SFRH/BD/893972012, SFRH/BD/86736/2012, SFRH/BPD/84508/2012 and SFRH/BPD/ $104629 / 2014$, attributed to AV, DS, AC, and DB, respectively, and Unit funding UID/AGR/04129/2013.

Hindorf, H., and Omondi, C. O. (2011). A review of three major fungal diseases of Coffea arabica L. in the rainforests of Ethiopia and progress in breeding for resistance in Kenya. J. Adv. Res. 2, 109-120. doi: 10.1016/j.jare.2010.08.006

Ismail, A. M., Cirvilleri, G.,Yaseen, T., Epifani, F., Perrone, G., and Polizzi, G. (2015). Characterisation of Colletotrichum species causing anthracnose disease of mango in Italy. J. Plant Pathol. 97, 167-171. doi: 10.4454/JPP.V97I1.011

Jayawardena, R. S., Hyde, K. D., Jeewon, R., Li, X. H., Liu, M., and Yan, J. Y. (2016). Mycosphere essay 6: why is it important to correctly name Colletotrichum species? Mycosphere 7, 1076-1092. doi: 10.5943/mycosphere/si/2c/1

Liu, F., Damm, U., Cai, L., and Crous, P. W. (2013). Species of the Colletotrichum gloeosporioides complex associated with anthracnose diseases of Proteaceae. Fungal Divers. 61, 89-105. doi: 10.1007/s13225-013-0249-2

Mosca, S., Li Destri Nicosia, M. G., Cacciola, S. O., and Schena, L. (2014). Molecular analysis of Colletotrichum species in the carposphere and phyllosphere of olive. PLoS ONE 9:e114031. doi: 10.1371/journal.pone.0114031

Nutman, F. J., and Roberts, F. M. (1960). Investigations on a disease of Coffea arabica caused by a form of Colletotrichum coffeanum Noack I. Some factors affecting infection by the pathogen. Trans. Br. Mycol. Soc. 43, 489-505. doi: 10.1016/S0007-1536(60)80031-9

Perrone, G., Magistà, D., and Ismail, A. M. (2016). First report of Colletotrichum kahawae subsp. ciggaro on mandarin in Italy. J. Plant Pathol. 98:12. doi: 10.4454/JPP.V98I3.012

Pires, A. S., Azinheira, H. G., Cabral, A., Tavares, S., Tavares, D., Castro, M., et al. (2016). Cytogenomic characterization of Colletotrichum kahawae, the causal agent of coffee berry disease, reveals diversity in minichromosome profiles and genome size expansion. Plant Pathol. 65, 968-977. doi: 10.1111/ppa.12479

Prihastuti, H., Cai, L., Chen, H., McKenzie, E. H. C., and Hyde, K. D. (2009). Characterisation of Colletotrichum species associated with coffee berries in northern Thailand. Fungal Divers. 39, 89-109. 
Rayner, R. W. (1952). Coffee berry disease. a survey of investigations carried out up to 1950. E. Afr. Agric. J. 17, 130-158. doi: 10.1080/03670074.1952.116 64802

Schena, L., Mosca, S., Cacciola, S. O., Faedda, R., Sanzani, S. M., Agosteo, G. E., et al. (2014). Species of the Colletotrichum gloeosporioides and C. boninense complexes associated with olive anthracnose. Plant Pathol. 63, 437-446. doi: $10.1111 /$ ppa.12110

Silva, D. N., Talhinhas, P., Cai, L., Manuel, L., Gichuru, E. K., Loureiro, A., et al. (2012b). Host-jump drives rapid and recent ecological speciation of the emergent fungal pathogen Colletotrichum kahawae. Mol. Ecol. 21, 2655-2670. doi: 10.1111/j.1365-294X.2012.05557.x

Silva, D. N., Talhinhas, P., Várzea, V., Cai, L., Paulo, O. S., and Batista, D. (2012a). Application of the Apn1/MAT locus to improve the systematics of the Colletotrichum gloeosporioides complex: an example from coffee (Coffea spp.) hosts. Mycologia 104, 396-409. doi: 10.3852/11-145

Silva, M. C., Várzea, V., Guerra-Guimarães, L., Azinheira, H. G., Fernandez, D., Petitot, A. S., et al. (2006). Coffee resistance to the main diseases: leaf rust and coffee berry disease. Braz. J. Plant Physiol. 18, 119-147. doi: 10.1590/s1677-04202006000100010

Taylor, J. W., Jacobson, D. J., Kroken, S., Kasuga, T., Geiser, D. M., Hibbett, D. S., et al. (2000). Phylogenetic species recognition and species concepts in fungi. Fungal Genet. Biol. 31, 21-32. doi: 10.1006/fgbi.2000.1228

Vossen, H. A. M., and Walyaro, D. J. (2009). Additional evidence for oligogenic inheritance of durable resistance to coffee berry disease (Colletotrichum kahawae) in arabica coffee (Coffea arabica L.). Euphytica 165, 105-111. doi: $10.1007 /$ s10681-008-9769-3
Varzea, V. M. P., Rodrigues, C. J. Jr., and Lewis, B. G. (2002). Distinguishing characteristics and vegetative compatibility of Colletotrichum kahawae in comparison with other related species from coffee. Plant Pathol. 51, 202-207. doi: 10.1046/j.1365-3059.2002.00622.x

Vieira, A., Silva, D. N., Várzea, V., Silva, M. C., Paulo, O. S., and Batista, D. (2016). "Adaptation of Colletotrichum kahawae to Coffea arabica: a genomic approach", in 2nd cE3c Annual Meeting: Frontiers in E3, Book of Abstracts, ed FCUL (Lisboa), 60-61.

Waller, J. M., Bridge, P. D., Black, R., and Hakiza, G. (1993). Characterization of the coffee berry disease pathogen, Colletotrichum kahawae sp. nov. Mycol. Res. 97, 989-994. doi: 10.1016/S0953-7562(09)80867-8

Weir, B. S., Johnston, P. R., and Damm, U. (2012). The Colletotrichum gloeosporioides species complex. Stud. Mycol. 73, 115-180. doi: 10.3114/ $\operatorname{sim} 0011$

Conflict of Interest Statement: The authors declare that the research was conducted in the absence of any commercial or financial relationships that could be construed as a potential conflict of interest.

Copyright (C) 2017 Batista, Silva, Vieira, Cabral, Pires, Loureiro, Guerra-Guimarães, Pereira, Azinheira, Talhinhas, Silva and Várzea. This is an open-access article distributed under the terms of the Creative Commons Attribution License (CC BY). The use, distribution or reproduction in other forums is permitted, provided the original author(s) or licensor are credited and that the original publication in this journal is cited, in accordance with accepted academic practice. No use, distribution or reproduction is permitted which does not comply with these terms. 